\title{
Nível de degradação do solo por processo de voçorocamento em latossolo vermelho-amarelo, no Município de Corrente, Estado do Piauí, Nordeste do Brasil
}

\author{
Gleide Ellen dos Santos Clementino ${ }^{1}$, Bruna de Freitas Iwata ${ }^{2}$, \\ Dorgival Lustosa Filho $^{3}$, Tancio Gutier Ailan Costa ${ }^{4}$, Nayara \\ Caroline Moreira Leopoldo ${ }^{1}$, Ana Carla Ribeiro Maciel ${ }^{1}$
}

${ }^{1}$ Instituto Federal do Piauí. Curso de Tecnologia em Gestão Ambiental. Campus Corrente. Rua Projetada Trinta e Seis, 380. Nova Corrente. Corrente-PI, Brasil (CEP 64980-000). E-mail: gleideellen.15@gmail.com.

${ }^{2}$ Instituto Federal de Educação, Ciência e Tecnologia do Piauí. Campus Teresina Central. Praça da Liberdade, 1597. Centro. Teresina-PI, Brasil (CEP 64000-040).

3Universidade Estadual do Piauí. Curso de Bacharelado em Agronomia. Campus Deputado Jesualdo Cavalcanti. Avenida Joaquina Nogueira de Oliveira, S/№. Aeroporto. Corrente-PI, Brasil (CEP 64980-000).

${ }^{4}$ Universidade Federal do Ceará. Mestrado em Ciência do Solo. Campus Pici. Fortaleza-CE (CEP 60455-900).

Resumo. O mau uso e o não planejamento no processo de ocupação do solo no meio rural têm provocado graves prejuízos, intensificando os processos erosivos. Desta forma o objetivo deste trabalho é verificar o nível de degradação do solo sob voçorocamento no cerrado piauiense. A pesquisa foi realizada no Município de Corrente, Estado do Piauí, Nordeste do Brasil, desenvolvida em área de voçorocamento situada na zona rural. A coleta de solos foi realizada em áreas de mata nativa e na área degradada, para a caracterização e avaliação da qualidade física e química do solo, e posterior comparação após adoção do processo de recuperação do solo, classificado como. Latossolo VermelhoAmarelo. 0 estudo verificou que quanto à densidade do solo não houve variação significativa entre mata nativa e área degradada, já em se tratando da umidade observou-se que a mata nativa apresentou maiores valores provavelmente em virtude da infiltração de água. Os dados obtidos de $\mathrm{pH}$ do solo da área nativa e degradada apresentaram valores médios considerados bons variando entre 6,17 e 6,39, respectivamente, diferindo dos padrões de Latossolos em Região de Cerrado. Os teores da matéria orgânica nas áreas selecionadas apresentaram uma pequena variação, sendo encontrada maior concentração na área degradada devido ao deposito de nutrientes possivelmente lixiviados durante a estação chuvosa. A transição de veículos, animais e pessoas na localidade são fatores que tem agravado e contribuído para o desprendimento do solo com feições erosivas. Diante disso fazendo-se necessário medidas corretivas para
Recebido: $23 / 05 / 2018$

Aceito: 09/08/2018

Publicado: $31 / 08 / 2018$

Acesso aberto

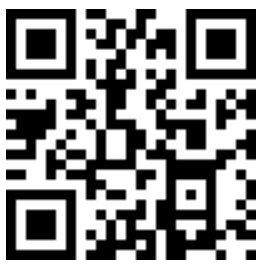

ORCID

(D) 0000-0003-2029-9997

Gleide Ellen dos

Santos Clementino

(1) 0000-0002-6465-9731

Bruna de Freitas Iwata 
minimizar tais problemáticas, como também apoio e parcerias para facilitar esse processo de recuperação.

Palavras-chave: Erosão do solo; Diagnóstico ambiental; Voçorocas.

\begin{abstract}
Soil degradation level by gully process in red-yellow latosol, in the Municipality of Corrente, Piauí State, Northeast Brazil. The misuse and planning in the process of land in rural areas have caused severe damage, intensifying the erosion processes. The aim of this study is to verify the level of soil degradation under gully process in the Cerrado of Piauí. The survey was conducted in the Municipality of Corrente, Piauí State of Piauí, Northeast Brazil, developed in the area of gully process located in the countryside. The collection of soils was held in areas of native forest and degraded area, for characterization and evaluation of physical quality and soil chemistry, and later comparison after adoption of the recovery process of the soil, classified as red-yellow latosol. The study found that as the density of the soil there was no significant variation between native forests and degraded area in the case of moisture it has been observed that the native forest presented higher values probably due to water infiltration. The data obtained from soil $\mathrm{pH}$ of native and degraded area average values considered good ranging from 6.17 and 6.39, respectively, differing patterns of presence of microaggregates in Cerrado Region. The levels of organic matter in selected areas showed a slight variation, being found greater concentration in the area degraded due to deposit of nutrients leached possibly during the rainy season. The transition from vehicles, animals and people in the area are factors that have aggravated and contributed to the detachment of soil with erosional features. Given that doing necessary corrective measures to minimize such problems, as well as support and partnerships to facilitate this process of recovery.
\end{abstract}

Keywords: Soil erosion; Environmental diagnosis; Gullies.
(D) $0000-0002-2023-7975$

Dorgival Lustosa Filho

(1) 0000-0002-0635-2651

Tancio Gutier Ailan

Costa

(1) 0000-0002-0979-0657

Nayara Caroline

Moreira Leopoldo

(1) 0000-0001-8742-4137

Ana Carla Ribeiro

Maciel

\section{Introdução}

O processo de degradação do solo
ocorre quando suas características
determinantes são modificadas negati-
vamente, principalmente pela retirada de
pequenas partículas ricas em nutrientes
do solo, promovendo o decréscimo da
fertilidade, pela redução das produções
ou por crescentes necessidades da
reposição de fertilizantes e corretivos
(Santos et al., 2010).
O nível de degradação do solo é
definido quando se determina a
espessura de um horizonte superficial e

este sendo comparando com outros perfis de solos de áreas próximas apresentem os mesmos aspectos da avaliação, ainda com a presença de cobertura vegetal. E neste caso, se a área avaliada apresentar horizonte superficial menos profundo ou pouco desenvolvido, o processo de degradação possivelmente irá ocorrer (Chaves et al., 2012).

Siqueira et al. (2008), citam perdas da matéria orgânica, mudanças na estrutura, lixiviação de nutrientes, permeabilidade, densidade do solo e porosidade (resultantes de erosão hídrica) como processos importantes que 
causam a degradação do solo. Todos eles ligados à perda das características e atributos físicos, químicos e biológicos que determinam a boa qualidade do solo.

A erosão é um processo natural de formação da paisagem, que age continuamente na crosta terrestre, sendo sua ocorrência um processo de modificação e de formação do solo. A ação do homem, por meio da introdução de práticas que modificam o equilíbrio das condições naturais existentes nesse processo, pode proporcionar $\mathrm{o}$ surgimento de um estágio de erosão mais acelerado, fenômeno que traz grande preocupação pelo fato de seu processo ser rapidamente expansivo, trazendo prejuízos para a qualidade do solo, exploração agropecuárias e também diversas atividades socioambientais (Pruski, 2009).

Tótola e Chaer (2002) relatam que a qualidade do solo refere-se às boas condições para que o solo funcione adequadamente. Seu funcionamento depende da interação de processos químicos, físicos e biológicos, que mantêm um fluxo constante e uma natureza heterogênea. E a perda da qualidade do solo nestes aspectos provoca a redução da capacidade do solo em exercer suas funções diversas.

A qualidade do solo pode ser entendida como a capacidade que um solo especifica tende a funcionar dentro dos limites de um ecossistema manejado ou natural, que pode ser avaliada por meio de atributos específicos, os quais servirão como indicadores para avaliar a degradação e seu potencial de sustentabilidade como também o grau de alteração e ou reabilitação dos solos sob interferência antrópica drástica ou, até mesmo, natural, como o processo de voçorocamento, sobre o ambiente (Gomide, 2009).

Nesta perspectiva a voçoroca corresponde a um estágio mais avançado da erosão e está associada principalmente com a evolução do processo erosivo em locais que apresentam vulnerabilidade a esses fenômenos, apresen- tando uma forte relação com o uso do solo. A existência de um estágio de erosão avançado nos propõe a buscar técnicas para controla-lo de maneira mais eficiente e econômica viável, evitando assim, estragos ainda maiores (Rezende et al., 2011).

Segundo Soares Júnior e Ferreira (2007), a perda de solo por esses processos nas estradas tem grande poder de desenvolvimento, visto a inexistência de uma camada capaz de proteger a via da ação do tempo e por isso, se observa grandes áreas de voçorocamento na beira dessas estradas. Logo, o mau uso e o não planejamento no processo de ocupação do solo no meio rural têm provocado graves prejuízos, intensificando os processos erosivos. Desta forma objetivou-se com está pesquisa diagnosticar o nível de degradação do solo sob voçorocamento no Cerrado do extremo sul do Estado do Piauí.

\section{Material e métodos}

\section{estudo \\ Caracterização da área de}

A pesquisa foi realizada no Município de Corrente, Estado do Piauí, localiza-se a $10^{\circ} 26^{\prime} 36^{\prime \prime}$ de latitude S e $45^{\circ} 09^{\prime} 44^{\prime \prime}$ de longitude $\mathrm{W}$, estando a uma altitude de $438 \mathrm{~m}$. Sua população estimada é de cerca de 26.149 habitantes, estando inserido na Microrregião das Chapadas do Extremo Sul Piauiense compreendendo uma área de $3.048,447 \mathrm{~km}^{2}$ (IBGE, 2016). 0 clima, de acordo com a classificação de Köppen é do tipo AW, Tropical Subúmido com estação seca (Köppen, 1936). Os totais pluviométricos anuais ficam entre $750 \mathrm{e}$ $1.400 \mathrm{~mm}$, com temperatura média anual de $26^{\circ} \mathrm{C}$. Tem como predominância biomática ou fitogeográfica o Cerrado (IBGE, 2016).

A escolha do local caracterização do nível de degradação deveu-se a uma maior representatividade de processos erosivos em estágios avançados recorrente na região (Figura 1). 


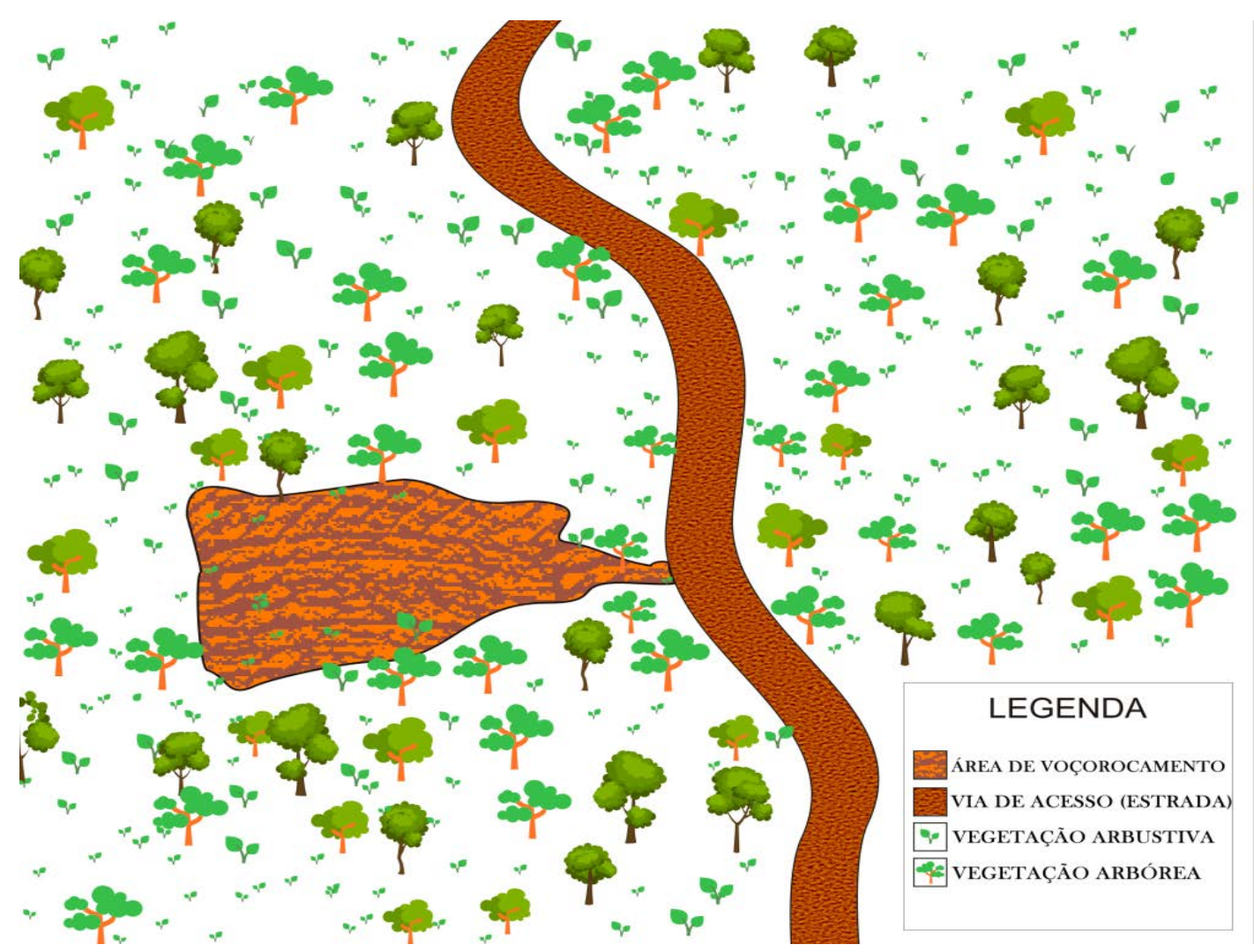

Figura 1. Croqui de localização da área de voçorocamento, localizada em região rural do município de Corrente, extremo Sul do Piauí. Elaborado por: Laécio Miranda Cunha, 2017.

Conforme características pedológicas da região há um predomínio de solos da classe Latossolo VermelhoAmarelo (LVA) conforme a Embrapa (2006).

\section{Procedimentos diagnósticos e caracterização da área de voçorocamento}

O diagnóstico da área estudada foi realizado através de levantamento de campo fazendo-se o uso de registro fotográfico do estágio de voçorocamento, análises dos perfis pedológicos da área por meio de descrições morfológicas conforme (EMBRAPA, 2013) e avaliação das dimensões da voçoroca com estimativa de ausência de solo pelo estágio desenvolvido conforme as dimensões obtidas. Além disso, foram realizadas coletas de solo em áreas sob mata nativa do Cerrado (MNC) e área degradada (AD) por erosão, para a caracterização e avaliação física e química do solo. Os atributos físicos diagnósticos analisados correspondem a densidade e umidade do solo e os químicos a matéria orgânica particulada (MOP) e $\mathrm{pH}$.

\section{Densidade aparente do solo}

A densidade do solo foi quantificada a partir de amostras com estrutura preservada, coletadas em cilindros de volume de 269,33 $\mathrm{cm}^{3}$, e secas a $105^{\circ} \mathrm{C}$ até massa constante (Blake e Hartge, 1986). Foram coletadas seis amostras seguidas de três repetições em cada ambiente (Mata nativa do Cerrado e área degradada), buscando correlacionar os dados obtidos com a vegetação e atributos ambientais. A densidade do solo (Ds) foi obtida pela relação entre o peso seco da amostra de solo coletada e o volume do anel volumétrico, através da expressão: 


$$
D s=\frac{a}{b}
$$

Onde:

Ds = densidade do solo $\left(\mathrm{kg} \cdot \mathrm{dm}^{-3}\right)$;

$\mathrm{a}=$ massa da amostra seca a $105^{\circ} \mathrm{C}(\mathrm{kg})$;

$\mathrm{b}=$ volume do anel ou cilindro $\left(\mathrm{dm}^{3}\right)$.

\section{Umidade do solo}

A umidade do solo (\%) foi determinada conforme EMBRAPA (1997). Após a retirada das amostras no campo, as mesmas foram pesadas para que todas elas tivessem uma massa definida de cem gramas, obtendo a umidade de forma direta. Para a determinação da umidade do solo utilizou-se da equação:

$$
U=\frac{M u-M s}{M s} \cdot 100
$$

Sendo:

U - Umidade do solo a base de massa (\%);

$\mathrm{Mu}$ - massa do solo úmido (g);

Ms - massa de solo seco (g). (MOP)

Matéria Orgânica Particulada

A matéria orgânica particulada (MOP) foi analisada através do fracionamento densimétrico da matéria orgânica do solo conforme adaptação da metodologia de Liao et al. (2006). Tal metodologia tem como princípio a separação de frações da MOS (Fração Leve e Fração Pesada) com base na densidade dos componentes do solo em meio líquido de densidade conhecida (Liao et al., 2006). Foram fracionadas $10 \mathrm{~g}$ de solo em solução de $50 \mathrm{~mL}$ de água destilada, e em seguida realizada o cálculo para obtenção do percentual da fração leve da matéria orgânica equivalente a MOP.

\section{pH do solo}

Para determinar o $\mathrm{pH}$ do solo, foi utilizado o método de determinação de
pH em água, segundo Claessen et al. (1997). Em que se pesou em um béquer $10 \mathrm{~g}$ de solo (TFSE) de cada amostra e foram adicionados $10 \mathrm{~mL}$ de água destilada. Após 30 min de agitação fez-se a leitura através de pHmetro (modelo mPA-210), previamente calibrado.

\section{Análise estatística dos dados}

Os dados foram submetidos à comparação das médias dos atributos de qualidade do solo, realizados por meio do Teste de Tukey a $5 \%$, utilizando o pacote estatístico ASSISTAT 7.7.

\section{Resultados e discussão}

No diagnóstico do processo de voçorocamento da área de estudo verificou-se que o processo erosivo encontra-se em um elevado nível de degradação, com severas perdas de sedimentos e forte fluxo de enxurrada no período chuvoso da região. Caracterizando um processo de erosão acelerada (Figura 2).

O nível de degradação está relacionado com as dimensões aproximadas da voçoroca, visto que os valores médios obtidos correspondem a $13,70 \mathrm{~m}$ de comprimento, largura de 8,50 m e profundidade de 1,60 m. Com base nisso estimou-se a ausência de um volume de solo de aproximadamente $115,08 \mathrm{~m}^{3}$ possivelmente decorrente da perda de sedimentos pela velocidade da enxurrada durante o período de máxima precipitação e pela declividade do terreno. Dadalto et al. (1990) relatam que a velocidade de enxurrada influencia significativamente a quantidade de sedimento transportado, ou seja, quanto maiores a declividade e o comprimento do segmento, maior será a velocidade da enxurrada e, consequentemente, a quantidade de material transportado. E neste caso, à medida que a precipitação aumenta, ocorre incremento no volume de enxurrada e, por conseguinte, na perda de solo. 


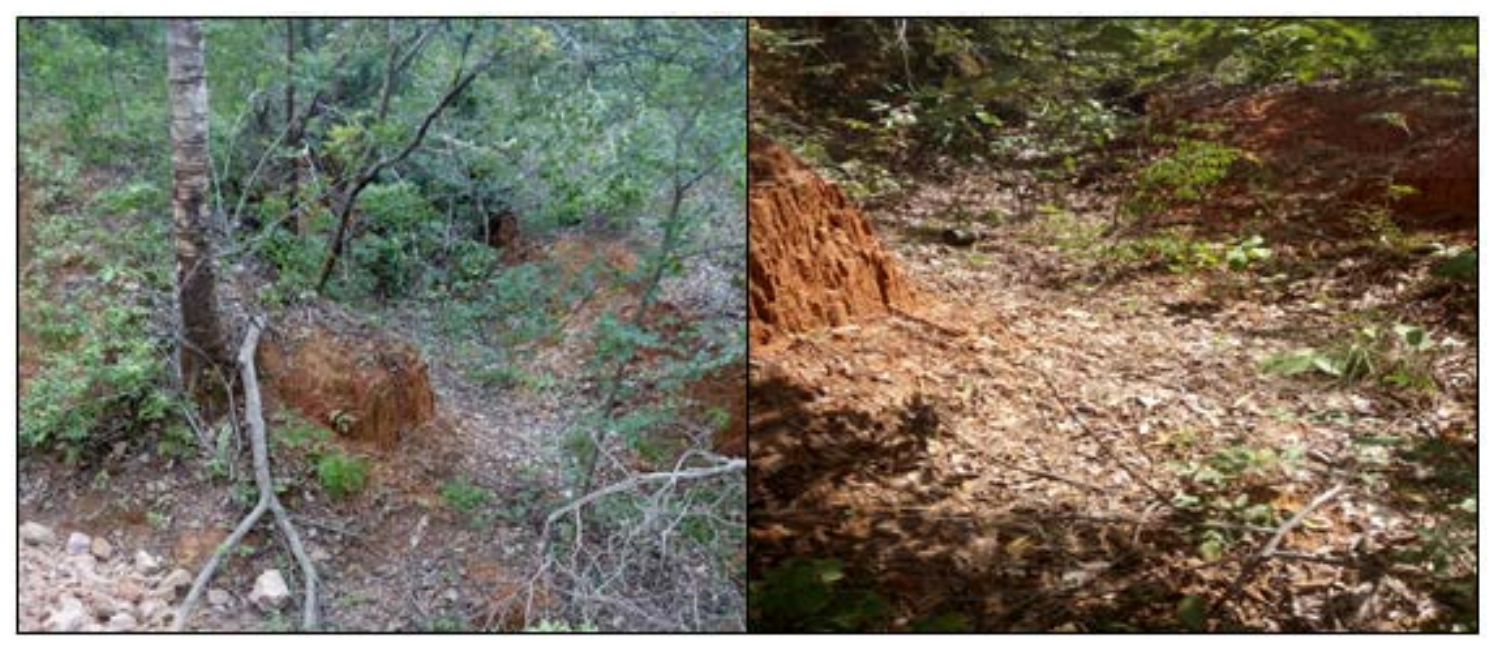

Figura 2. Processo de erosão acelerada na área de voçorocamento localizada em região rural do município de Corrente, extremo Sul do Piauí. Fonte: Autores, 2017.

Quanto às descrições morfológicas percebeu-se que os perfis estudados são completos, com transição gradual entre horizontes em cada perfil, significativa presença de raízes no horizonte superficial (em alguns casos expostas), coloração avermelhada, textura aparente argilosa. Foi verificada também uma presença marcante de canais de drenagem com elevado fluxo de água conduzido para a voçoroca (Figura 3).

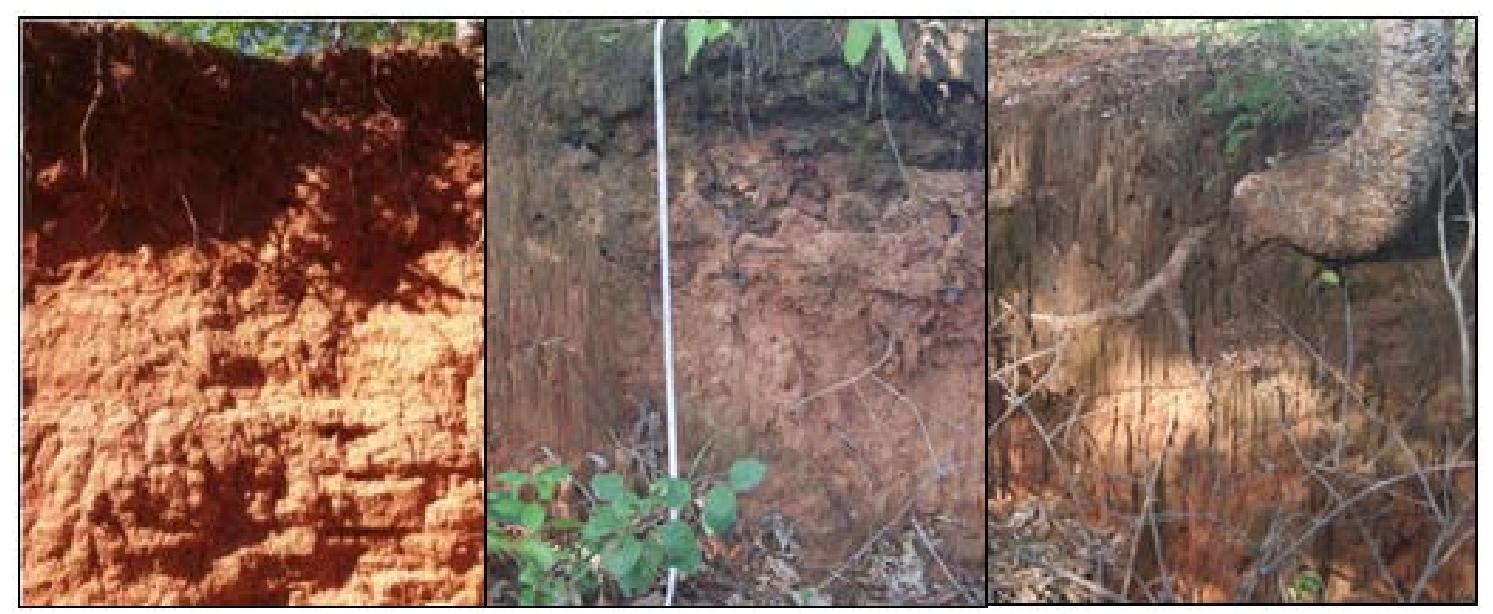

Figura 3. Perfil lateral de voçoroca localizada em região rural do Município de Corrente, extremo Sul do Piauí.

\begin{abstract}
Conforme a descrição morfológica pode-se notar que o processo de degradação é fortemente atuante na área de voçorocamento, tendo
\end{abstract}

em vista principalmente a marcante presença de canais de drenagem com elevado fluxo de água e acentuada exposição das raízes no horizonte 
superficial, o que mostra que tal realidade está relacionada com um nível de degradação acentuado nessas áreas. Além disso, quanto maior for a exposição das raízes nos horizontes superficiais maior será a perda de solo por erosão, uma vez que as mesmas servem como base para sustentar o solo e evitar o desprendimento de sedimentos sólidos e consequentemente o tombamento das árvores. Isso é reforçado por resultados encontrados por Albuquerque (2007) ao estudar agentes e processos erosivos em voçorocas, relatando que houve uma maior perda de solo ocasionada pelo "efeito alavanca" decorrente da perda da capacidade de sustentação do solo pelas raízes das árvores.

\section{Densidade e umidade do solo}

Quanto à densidade do solo não houve variação significativa entre mata nativa e a área degradada. Essa similaridade pode ter ocorrido devido à presença da matéria orgânica na voçoroca o que contribui para a redução dos valores de densidade do solo. Isso porque a matéria orgânica deixa o solo mais friável, ou seja, provavelmente a voçoroca recebe uma carga de matérias que influencia nesse processo, deixando o solo mais solto fazendo com que a densidade se torne similar a área de mata nativa. A Tabela 1 mostra que a mata nativa tem uma densidade um pouco menor em relação ao voçoroca mento, podendo estar relacionado com o material orgânico que está se depositando nessa cava. No entanto, destaca-se que apesar de ocorrerem similares valores de densidade na área da cava em relação à área nativa, o material superficial do solo fora removido por perda e arraste de material.

Salienta-se ainda, conforme Viana et al. (2011) que há influência tanto direta como indireta da matéria orgânica sob diversas características do solo, tendo em vista que teores baixos de carbono orgânico total, ou mesmo a sua redução, estão relacionados à degradação física dos solos.

Comparando a área de mata nativa do Cerrado com a de voçorocamento, observou-se que a MNC apresentou maiores valores de umidade em virtude, provavelmente, da infiltração mais eficiente de água, uma vez que há presença de vegetação, na qual as raízes contribuem para tal processo. Na área de voçorocamento tem-se uma grande perda de volume d'água, por ser uma área que ajuda o escoamento superficial, como também a perda física dos sedimentos daquele ambiente. Quimicamente pode se ter um ambiente rico, porque ele serve de deposito para todos os ambientes próximos, mais fisicamente ele se torna um problema pela desestruturação e perda de sedimento.

Tabela 1. Densidade e Umidade do solo (Ds) sob áreas de mata nativa do Cerrado (MNC) e área degradada (AD).

\begin{tabular}{ccc}
\hline \multirow{2}{*}{ ÁREAS } & $\begin{array}{c}\text { DENSIDADE } \\
\left(\mathbf{g . c m}^{-3}\right)\end{array}$ & $\begin{array}{c}\text { UMIDADE } \\
\text { (\%) }\end{array}$ \\
\cline { 2 - 3 } & $\mathbf{0 . 0 0 - 0 . 2 0 m}$ & $12.30^{\mathrm{b}}$ \\
MNC & $1.05^{\mathrm{a}}$ & $17.20^{\mathrm{a}}$ \\
\hline
\end{tabular}

Densidade aparente $\left(\mathrm{g} \mathrm{cm}^{-3}\right)$ do solo. Valores seguidos de letras iguais não diferem entre si Tukey, ao nível de $5 \%$ de probabilidade de erro. 
Beyene et al. (2010) Afirma que a desestruturação física do solo, aliada à redução da rugosidade (macro e micro), condiciona uma reduzida taxa de infiltração, causando um déficit hidrológico com o aumento no escoamento superficial. Isso representa um forte impacto na hidrologia $e$ desencadeia processos de degradação do solo e da água.

\section{pH do solo}

Os resultados obtidos para o $\mathrm{pH}$ do solo da MNC e AD apresentaram valores relativamente ácidos, variando entre 6,17 e 6,39, respectivamente (Figura 4). Essa similaridade pode ocorrer devida sua área adjacente ser próxima ao voçorocamento, onde pela declividade tem-se um arraste de material para essa voçoroca, sendo uma área de acumulo de nutrientes que estão equilibrando o $\mathrm{pH}$.

A acidez dos solos destaca 0 efeito de elementos que podem passar a atuar como tóxicos para as plantas como o alumínio, o ferro e o manganês, diminuindo também a presença de nutrientes (Oliveira et al, 2005). A faixa de $\mathrm{pH}$ entre 5,8 e 6,2 apresentam uma maior disponibilidade pois a maioria dos nutrientes essenciais então disponíveis para as culturas. Em pH mais elevado os macronutrientes como nitrogênio, fósforo, potássio, cálcio, magnésio e enxofre são mais disponíveis em relação à tolerância da maioria das plantas (EMBRAPA, 2004).

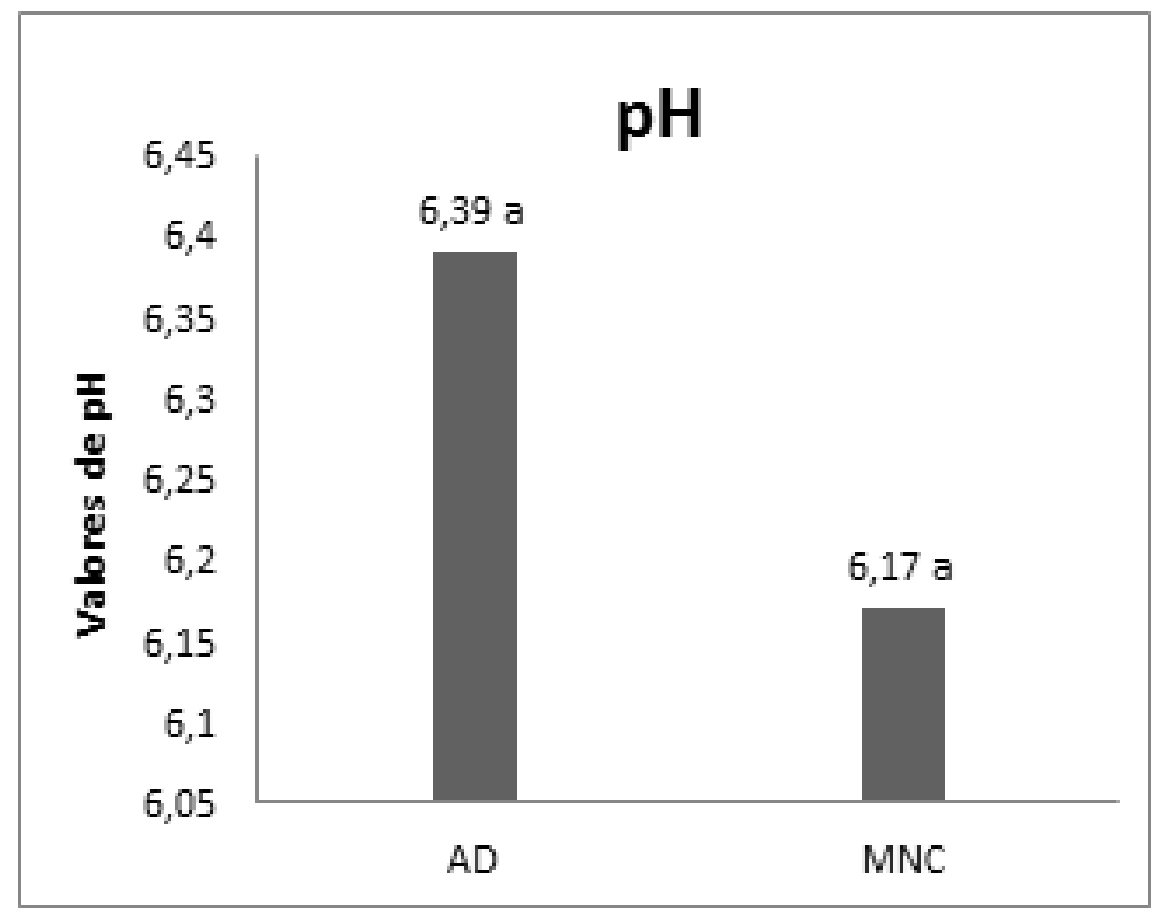

Figura 4. Valores de $\mathrm{pH}$ sob áreas de mata nativa do Cerrado e área degradada. Valores seguidos de letras iguais não diferem entre si Tukey, ao nível de $5 \%$ de probabilidade de erro.

(MOP)

\section{Matéria orgânica particulada}

De acordo com a Figura 10, os teores da matéria orgânica nas áreas selecionadas apresentaram uma pequena variação, sendo encontrada maior concentração na área degradada. A concentração de matéria orgânica está 
relacionada ao deposito de nutrientes possivelmente lixiviados durante a estação chuvosa. Os teores de matéria orgânica em áreas degradadas geralmente são baixos, devido principalmente à falta de cobertura vegetal. No entanto isso não acontece na área de voçorocamento, pelo fato da declividade do terreno que traz todos os sedimentos carreados no período chuvoso. 0 que contribuirá na recuperação dessa área, já que ela desempenha uma função importante para a qualidade e fertilidade do solo.

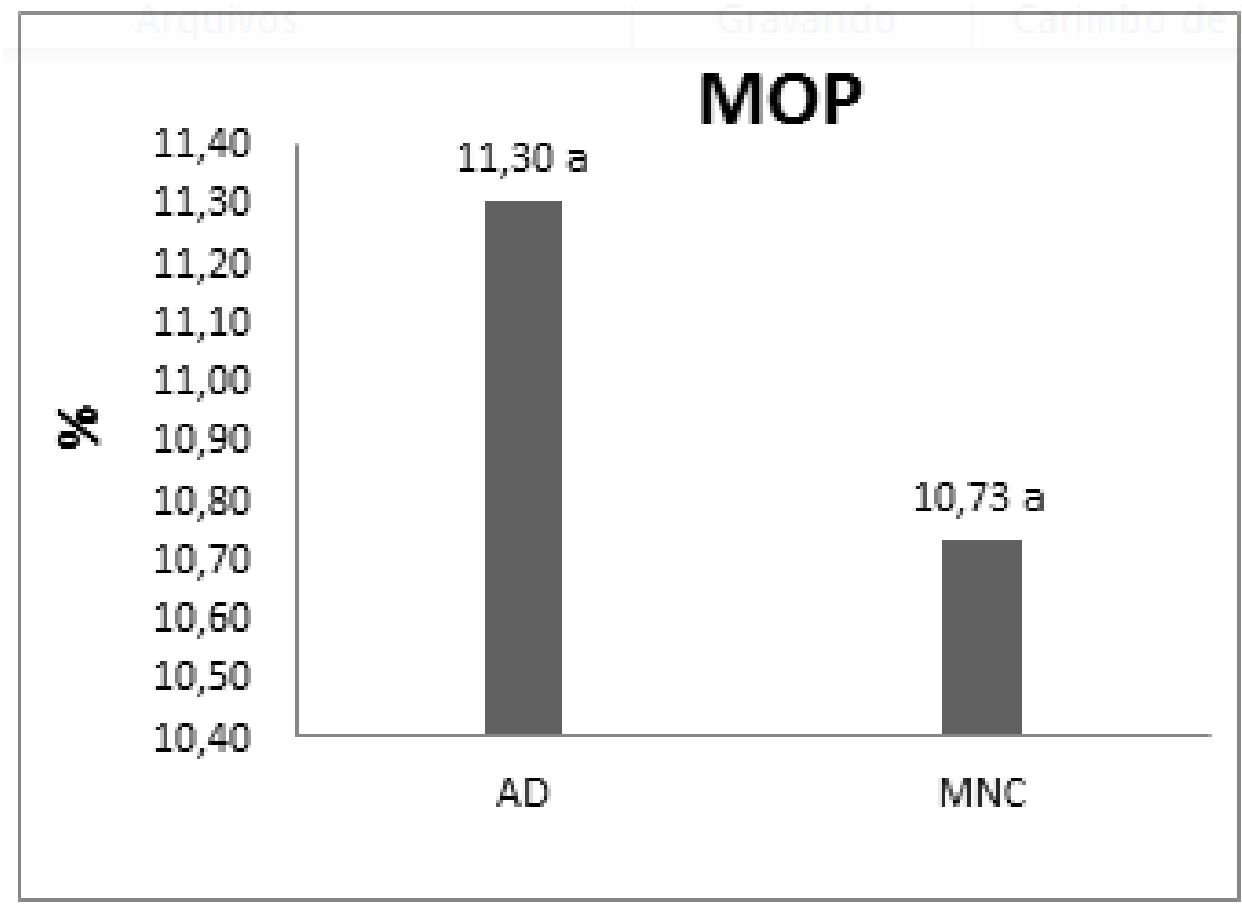

Figura 5. Teores de matéria orgânica particulada nas áreas de mata nativa do Cerrado e área degradada. Valores seguidos de letras iguais não diferem entre si Tukey, ao nível de 5\% de probabilidade de erro.

Segundo Cirilo (2009), na área degradada à concentração de matéria orgânica pode estar relacionado a pontos de solo exposto, possivelmente lixiviados durante a estação chuvosa. Os teores de matéria orgânica em áreas degradadas geralmente são baixos, devido principalmente a falta de cobertura vegetal. No entanto, na área em estudo os teores foram relativamente acima do ideal, 10 g.kg-1.

A voçoroca estudada está em estagio bem avançado de degradação, o solo já está exposto, e vulnerável a fortes que carregam cada vez mais partes.
Observa-se ainda o caminho percorrido de forma linearmente devido à velocidade das águas agravando as feições do solo. A transição de veículos, animais e pessoas na localidade são fatores que tem agravado e contribuído para o desprendimento do solo com feições erosivas.

\section{Considerações finais}

0 processo erosivo estudado encontra-se em constante evolução, onde se observa perda de solo das paredes laterais. 
Não houve variação da densidade do solo entre a mata nativa e a área degradada podendo ser relacionada presença da matéria orgânica reduzindo os valores de densidade do solo. Já a umidade apresentou maiores valores na mata, provavelmente pela infiltração mais eficiente de água, uma vez que há presença de vegetação, na qual as raízes contribuem para tal processo.

$\mathrm{O} \mathrm{pH}$ do solo apresentou valores relativamente ácidos, tanto na área nativa quanto na área degradada.

Os teores da matéria orgânica nas áreas selecionadas apresentaram uma pequena variação relacionada ao deposito de nutrientes possivelmente lixiviados durante a estação chuvosa.

Diante disso faz-se necessárias medidas corretivas para minimizar tais problemáticas, como também apoio e parcerias para facilitar esse processo de recuperação.

Pensando nisso, será realizado um estudo preliminar onde serão desenvolvidas técnicas de recuperação na voçoroca estuda como uma segunda proposta de intervenção de recuperação após diagnostico da área.

\section{Referências}

Albuquerque, F. N. Agentes, processos e feições erosivas em voçoroca conectada à rede de drenagem do Rio Coreaú, em Coreaú, Ceará. Revista da Casa da Geografia de Sobral, v. 8/9, n. 1, p. 11-20, 2007. Disponível em: <http://www.uvanet.br/rcgs/index.php/ RCGS/article/view/105/134>. Acesso em: 23 jan. 2018.

Beyene, T; Lettenmaier, D. P.; Kabat, P. Hydrologic impacts of climate change on the Nile River Basin: Implications of the IPCC scenarios 2007. Climate Change, v. 100, n. $3 / 4$, p. 433-461, 2010. https://doi.org/ 10.1007/s10584-009-9693-0

Blake, G. R.; Hartge, K. H. Particle density. In: Klute, A. (Ed.). Methods of soil analysis. 2. ed. Madison, American Society of Agronomy, Soil Science Society of America, 1986. pt. 1. p. 377-382.

Chaves, T. A.; Andrade, A. G.; Lima, J. A. S.; Portocarrero, H. Recuperação de áreas degradadas por erosão no meio rural. Niteroi: Programa Rio Rural, 2012. (Programa Rio Rural. Manual Técnico 34). Disponível em: <http://www.microbacias.rj. gov.br/conteudo/compartilhados/pesquisa_ participativa_apoio_tecnico/34

Recuperação de áreas degradadas por erosão no meio rural.pdf>. Acesso em: 23 jan. 2018.

Cirilo, P. A. M. Efeito da ação do homem na fertilidade dos solos da região de PalmasTO. Palmas: Faculdade Católica do Tocantins, 2009.

Claessen, M. E. C. (Org.). Manual de métodos de análise de solo. 2. ed. rev. atual. Rio de Janeiro: EMBRAPA-CNPS, 1997. (EMBRAPACNPS. Documentos, 1).

Dadalto, G. G.; Carmo Filho, O. G.; Castro, L. L. F. Captação de águas pluviais das estradas vicinais. Vitória: EMCAPA, 1990. (EMCAPA Documentos, 63).

EMBRAPA - Empresa Brasileira de Pesquisa Agropecuária. Centro Nacional de Pesquisa de Solos. Manual de métodos de análise de solo. 2. ed. rev. atual. Rio de Janeiro: EMBRAPA, 1997.

EMBRAPA - Empresa Brasileira de Pesquisa Agropecuária. Centro Nacional de Pesquisas de Solos. Produção de sementes sadias de feijão em várzeas tropicais. Rio de Janeiro: EMBRAPA, 2004.

EMBRAPA - Empresa Brasileira de Pesquisa Agropecuária. Centro Nacional de Pesquisa de Solos. Sistema Brasileiro de Classificação de Solos. 3. ed. Brasília: EMBRAPA, 2013.

EMBRAPA - Empresa Brasileira de Pesquisa Agropecuária. Centro Nacional de Pesquisa de Solos. Sistema Brasileiro de Classificação de Solos. 2. ed. Rio de Janeiro: EMBRAPA, 2006.

Ferreira, R. R. M.; Tavares Filho, J.; Ferreira, V. M. Efeitos de sistemas de manejo de pastagens nas propriedades físicas do solo. Semina: Ciências Agrárias, v. 31, n. 4, p. 913-932, 2010. Disponível em: <http://www.uel.br/revistas/uel/index.php/ semagrarias/article/viewFile/7597/6687>. Acesso em: 23 jan. 2018.

Gomide, P. H. O. Atributos físicos, químicos e biológicos do solo em ambientes de voçorocamento no Município de LavrasMG. Lavras: Universidade Federal de Lavras, 2009. (Dissertação de mestrado). 
IBGE - Instituto Brasileiro de Geografia e Estatísticas. Pesquisa Nacional de Saneamento Básico 2008. Rio de Janeiro: IBGE, 2016.

Köppen, W. Das geographische System der Klimate. In: Köppen, W.; Geiger, R. Handbuch der Klimatologie. Berlin: Gebrüder Borntraeger, 1936.

Liao, J. D.; Boutton, T. W.; Jastrow, J. D. Storage and dynamics of carbon and nitrogen in soil physical fractions following woody plant invasion of grassland. Soil Biology and Biochemistry, v. 38 , n. 11 , p. 3184-3196, 2006. https://doi.org/10.1016/j.soilbio. 2006.04.003

Oliveira, I. P; Costa K. A. P.; Rodrigues, C; Macedo, R. F.; Moreira, F. P; Santo, K. J. G. Manutenção e correção da fertilidade do solo para inserção do cerrado no processo produtivo. Revista Eletrônica Faculdade Montes Belos, v. 1, n. 1, p. 50-64, 2005.

Pruski, F. F. Conservação de solo e água: práticas mecânicas para o controle da erosão hídrica. Viçosa: Ed. Viçosa, 2009.

Rezende, W. S.; Gobbi, C. N.; Silva, C. E.; Almeida, J. R. Recuperação de voçorocas na zona rural do município de Mineiros (G0): financeiramente viável e ambientalmente sustentável. Revista Ibero-Americana de Ciências Ambientais, v. 2, n. 2, p. 64-81, 2011. https://doi.org/10.6008/ESS21796858.2011.002.0004

Santos, G. G.; Griebeler, N. P.; Oliveira, L. F. C. Chuvas intensas relacionadas à erosão hídrica. Revista Brasileira de Engenharia Agrícola e Ambiental, v. 14, n. 2, p. 115-123,
$2010 . \quad$ https://doi.org/10.1590/S141543662010000200001

Siqueira. J. O.; Soares. C. R. F. S.; Silva. C. A. Matéria orgânica e a sustentabilidade de sistemas agrícolas. In: Santos. G. A.; Silva. L. S.; Canellas, L. P.; Camargo. F. A. O. (Ed.). Fundamentos da matéria orgânica do solo: ecossistemas tropicais e subtropicais. 2. ed. Porto Alegre: Gênesis, 2008.

Soares Júnior, H. H.; Ferreira, O. M. Processos erosivos e perda de solo em estradas vicinais. Goiânia: Universidade Católica de Goiás, 2007.

Tótola, M. R.; Chaer, G. M. Microrganismos e processos microbiológicos como indicadores da qualidade dos solos. Tópicos em Ciências do Solo, Sociedade Brasileira de Ciências do Solo, v. 2, p. 195-276, 2002.

Viana, E. T.; Batista, M. A.; Tormena, C. A.; Costa, A. C. S.; Inoue, T. T. Atributos físicos e carbono orgânico em Latossolo Vermelho sob diferentes sistemas de uso e manejo. Revista Brasileira de Ciência do Solo, v. 35, n. 6, p. 2105-2114, 2011. https://doi.org/ 10.1590/S0100-06832011000600025

CC Informação da Licença: Este é um artigo Open Access distribuído sob os termos da Licença Creative Commons seja devidamente citada. 